\title{
Mitochondrial medicine: the future is now
}

\author{
Andrea L. Gropman \\ Division of Neurogenetics and Neurodevelopmental Pediatrics, Children's National Hospital and the George Washington \\ University School of Medicine and Health Sciences, Washington, DC 20010, USA. \\ Correspondence to: Dr. Andrea L. Gropman, Division of Neurogenetics and Neurodevelopmental Pediatrics, Children's \\ National Hospital and the George Washington University School of Medicine and Health Sciences, 111 Michigan Avenue, N.W., \\ Washington, DC 20010, USA. E-mail: agropman@childrensnational.org
}

How to cite this article: Gropman AL. Mitochondrial medicine: the future is now. J Trans/ Genet Genom 2021;5:62-3. http://dx.doi.org/10.20517/jtgg.2020.54

Received: 8 Dec 2020 Accepted: 9 Dec 2020 Available online: 2 Jan 2021

Academic Editor: Andrea L. Gropman Copy Editor: Cai-Hong Wang Production Editor: Jing Yu

The mitochondrial cytopathies are complex disorders that show phenotypic and genetic heterogeneity. Over the last decade, advances in mitochondrial research has earned it a "seat at the table" and its own specialty of medicine: "mitochondrial medicine". Considered the "powerhouses of the cell" and the major driver of cellular ATP, we can now appreciate the expanded role of the mitochondria in health and disease as an evolving and multidisciplinary area of research ${ }^{[1,2]}$. The scope of inherited and genetic mitochondrial disorders ranges from infancy onset global disease to organ specific disorders in adults such as myopathy and cardiac and liver disorders ${ }^{[3]}$. Secondary mitochondrial dysfunction has also been shown to play a role in many adult neurodegenerative conditions ${ }^{[4]}$.

This Special Issue about mitochondrial medicine focuses on the complexities of clinical phenotypes, diagnosis, genetics, genomics, and pharmacogenomics which may drive individualized and personalized treatment. Although genomic testing is standard in terms of the clinical panels that are available, the field is still expanding ${ }^{[5]}$. Low heteroplasmy in accessible tissues and variants of unknown significance still require functional studies to clarify their meaning and contribution to the phenotype and/or biochemical alterations in patients ${ }^{[6]}$.

In relation to disease, the emerging bioenergetic mitochondrial model suggests that mitochondrial defects contribute to the development of age-, stage-, and stress-related diseases by altering complex cellular and physiological functions ${ }^{[7]}$. 


\section{DECLARATIONS}

\section{Authors' contributions}

The author contributed solely to the article.

\section{Availability of data and materials}

Not applicable.

\section{Financial support and sponsorship}

None.

\section{Conflicts of interest}

The author declared that there are no conflicts of interest.

\section{Ethical approval and consent to participate}

Not applicable.

\section{Consent for publication}

Not applicable.

\section{Copyright}

(C) The Author(s) 2021.

\section{REFERENCES}

1. Picard M, Wallace DC, Burelle Y. The rise of mitochondria in medicine. Mitochondrion 2016;30:105-16.

2. Schirrmacher V. Mitochondria at work: new insights into regulation and dysregulation of cellular energy supply and metabolism. Biomedicines 2020;8:526.

3. DiMauro S. A brief history of mitochondrial pathologies. Int J Mol Sci 2019;20:5643.

4. Schon EA, Przedborski S. Mitochondria: the next (neurode)generation. Neuron 2011;70:1033-53.

5. Russell OM, Gorman GS, Lightowlers RN, Turnbull DM. Mitochondrial diseases: hope for the future. Cell 2020;181:168-88.

6. Duan M, Tu J, Lu Z. Recent advances in detecting mitochondrial DNA heteroplasmic variations. Molecules 2018;23:323.

7. Dillon LM, Williams SL, Hida A, et al. Increased mitochondrial biogenesis in muscle improves aging phenotypes in the mtDNA mutator mouse. Hum Mol Genet 2012;21:2288-97. 